\title{
Ectopia Cordis- A Rare Congenital Condition
}

\author{
Shrestha $\mathbf{R}^{1}$, Chhetri $\mathrm{S}^{\mathbf{1}}$, Regmi, $\mathrm{MC}^{\mathbf{1}}$, Basnet $\mathbf{P}^{1}$ \\ ${ }^{1}$ Department of OBGYN, BPKIHS, Dharan
}

Received: 12-Nov-2016; Accepted: 30-Mar-2017

Ectopia cordis is a rare congenital malformation and only few cases have been reported in literature previously. It is defined as the complete or partial evisceration of heart outside the thoracic cavity through the sternal defect. Most cases are sporadic. The classical presentation for the antenatal diagnosis on ultrasonography is a pulsating heart out of the thoracic cavity with absent chest wall.

\begin{abstract}
We reported three cases of ectopia cordis in the last one and half year in our institute. Two of them were diagnosed on ultrasound and the third case terminated for meningocele with severe oligohydramnios had associated ectopia cordis detected after delivery. All three were admitted via out patient department for termination. The first case live at birth had isolated thoracic ectopia cordis with birth weight of 2.4 kilograms, Apgar score of 7,8,9 and was delivered by caesarean section for failed induction while the other two were still birth and had thoraco-abdominal ectopia cordis. The live baby was taken to Sahid Gangalal hospital in Kathmandu by the visitors after two days of delivery and the baby underwent surgical intervention but had an unsuccessful outcome. Regarding the management of this condition, parental counseling for pregnancy termination is advised. Though few cases of surgical interventions for ectopia cordis have been reported, mortality rate is still very high.
\end{abstract}

Keywords: antenatal diagnosis, congenital malformation, ectopia cordis, meningocele, oligohydramnios

DOI: http://dx.doi.org/10.3126/njog.v12i1.18984

\section{INTRODUCTION}

The term "Ectopia Cordis" is derived from Greek word "ectopos = out of position" and latin word "cordis = heart". It is defined as the complete or partial evisceration of heart outside the thoracic cavity through the sternal defect. ${ }^{1}$ Ectopia cordis in human was first reported in 1671 by Neil Stensen. Later, the term "Ectopia Cordis" was coined by Haller in $1706 .{ }^{2}$ The estimated prevalence rate of ectopia cordis is 8 per million births. American Heart Association has given two major criteria for the diagnosis of ectopia cordis:

(1) The heart by truly extrathoracic, not merely part of a herniation and

(2) The heart remains above the diaphragm, not passing through a diaphragmatic defect. ${ }^{3}$

\section{CASE 1}

A 22 years pregnant woman from Baniyani-4 was an unbooked, immunized, primigravida at 34 weeks 1 day period of gestation. She was referred from outpatient department on $1^{\text {st }}$ of Chaitra, 2071 for admission in antenatal ward and termination of pregnancy with ultrasound report of single live

\section{CORRESPONDENCE}

Dr Ramesh Shrestha, BPKIHS, Dharan

Cell\#: +977-9842352484,

Email: stharamesh007@gmail.com intrauterine fetus of 35 weeks 3 days with breech, fundo-posterior placenta, normal liquor volume with normally beating heart out of the thoracic cavity with absent chest wall suggestive of ectopia cordis.

Her menstrual, past, family, contraceptive and personal history were unremarkable with no history of fever, intake of teratogenic drugs or radiation exposure in her antenatal period. During admission, her general condition was fair, vitals stable. On per abdominal examination, uterus was 36 weeks, relaxed, breech presentation with normal fetal heart rate. On per vaginal examination, pelvis was adequate with Bishop's score of three. Her investigation report were normal. She was induced with two cycles of 25 ug misoprostol followed by mechanical induction with Foley catheter followed by augmentation with oxytocin for 12 hours. She was taken for cesarean section for failed induction and delivered a male baby weighing 2.4kilograms with Apgar score $=7,8,9$ at 5:05 am on $7^{\text {th }}$ of Chaitra by breech extraction with normally beating heart out of the thoracic cavity with no associated gross anomalies with features suggestive of thoracic ectopia cordis. On repeated counseling, the baby was taken to Sahid Gangalal hospital in Kathmandu by the visitors after two days of delivery and the baby underwent surgical intervention on $10^{\text {th }}$ of chaitra but has an unsuccessful outcome. 


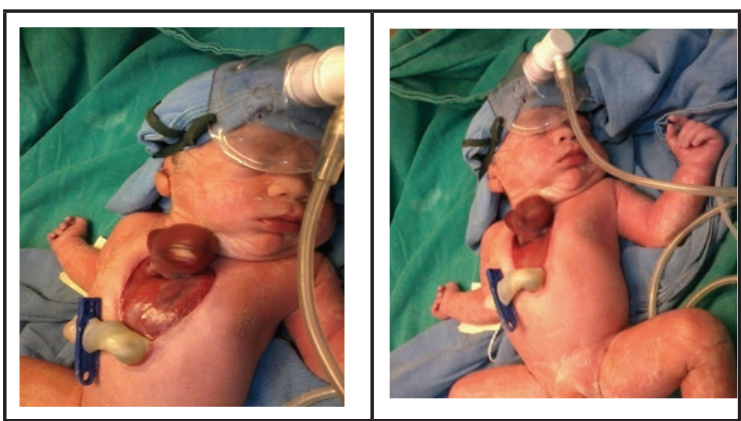

CASE 2

A 25 years pregnant woman from Dangibari-5 was admitted in gynae ward via outpatient department on $31^{\text {st }}$ shrawan, 2072 for termination of pregnancy with ultrasound diagnosis of single live intrauterine fetus of 25 weeks 1 day period of gestation with defect in lower chest and anterior abdominal wall with pericardium, liver and urinary bladder exposed externallyectopiacordis with deformed foot and lumbar lordosis. She was unbooked, immunised $\mathrm{G}_{3} \mathrm{P}_{2} \mathrm{~L}_{2}$ at 28 weeks with previous two vaginal deliveries with no significant past, personal and family history. She had no history of antenatal radiation or teratogenic drugs exposure. Her investigation reports were normal. During admission, her general condition was fair, vitals were stable. On per abdominal examination, uterus was 24-26 weeks size. She was induced with mifepristone followed by misoprostol (100 ug) - three doses. She expelled a 800 grams fetus without signs of life with deficient lower chest wall and upper anterior abdominal wall- externally exposed heart with gastroschisis and limb deformities features suggestive of thoraco-abdominal ectopia cordis.

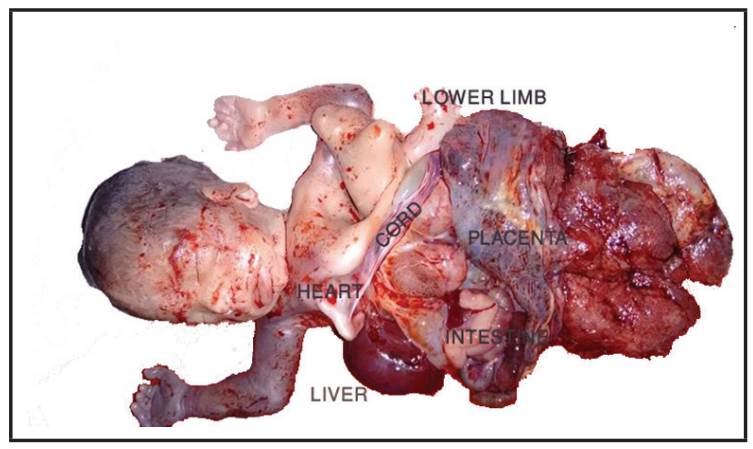

CASE 3

A 20 years unbooked, immunized, primigravida at 44 weeks 2 days period of gestation from Dhankuta was admitted on $29^{\text {th }}$ of baisakh, 2072 via emergency in latent stage of labour with the ultrasound diagnosis of single live intrauterine fetus at 29 weeks 2 days, cephalic, placenta at posterior upper uterine segment, estimated fetal weight=1072 grams, amniotic fluid index of $0.9 \mathrm{~cm}$ with spina bifida with protrusion of cystic component via defect at lumbosacral level - meningocele. Her family and past history were uneventful with no history of exposure to drugs and radiation in the antenatal period. Her admission vitals were normal. On per abdominal examination, uterus was 30 weeks size. Her investigation reports were normal except blood group was A-ve with husband $\mathrm{Rh}$ positive. The next day, she delivered spontaneously a still birth baby of 1.5 kilograms with undifferentiate sex with absent lower chest wall and anterior abdominal wall with protrusion of heart and abdominal viscera outside body cavity features suggestive of thoraco-abdominal ectopia cordis with gastroschisis. It also featured absence of right lower limb with meningocele, presence of two extra toes in left lower limb and short neck with suspected tracheal atresia.

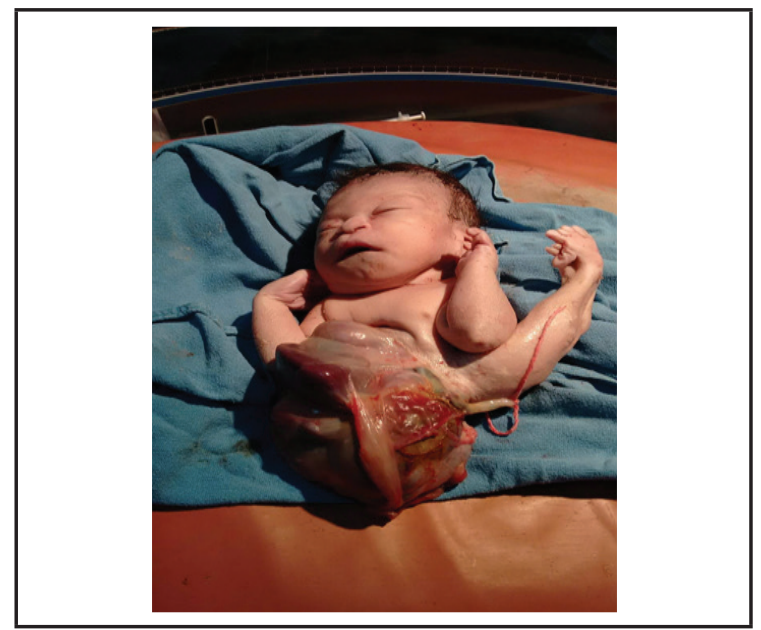

\section{COMMENT}

Most cases are sporadic in origin. It is probable that ectopia cordis originates during the very early stages of development, perhaps as early as the third week of embryonic life. ${ }^{2}$ Although the precise etiology of the disease is still unknown, it is thought to be due to improper development of the chest cavity's structure during the embryonic stage in which there is improper or incomplete fusion of two lateral body wall folds in the midline to form the ventral body wall by the end of $4^{\text {th }}$ week. ${ }^{4}$ A mechanical theory has also been explained for the origin of this condition in which early rupture of amnion or chorion and/or yolk sac (amniotic band) causes compression of the thorax which stop the midline fusion. ${ }^{5}$ Few literatures ${ }^{6}$ had also explained the possible association with trisomy 
13 , trisomy 18 , triploidy etc. with possibility of $\mathrm{X}$ linked recessive inheritance like gene linked to Xq2526.1 region.

The disease may occur as an isolated malposition of the heart or linked to a much larger cases of anterior body wall defects that involves the abdomen, thorax or both. The commonly associated abdominal wall defects include omphalocele and gastroschisis; thoracic wall defects include tetralogy of fallot, atrial septal defect, tricuspid atresia, double outlet right ventricle, ventricular septal defect, hypoplastic lung disease, diaphragmatic hernia and facial defects include cleft lip and cleft palate. ${ }^{7}$ The various types of ectopia cordis includes :- (a) Cervical Ectopia cordis (b) Thoracic Ectopia cordis (c) Thoracoabdominal ectopia cordis (d) Abdominal ectopia cordis with thoracic type is the commonest and cervical type the rarest. $^{2}$ Ectopia cordis is associated with sternal cleft, diaphragmatic hernia, omphalocele, and an intracardiac defect is known as Cantrell's pentalogy. ${ }^{4}$

The best method for the prenatal assessment is ultrasonography which reveals a pulsating mass outside the body cavity. It should be supplemented with prenatal echocardiography and Magnetic Resonance Imaging to detect intra-cardiac anomalies. ${ }^{8}$

Regarding the management, it is supplemented with parental counseling followed by pregnancy termination. The treatment options for ectopia cordis is limited due to rarity of the condition and speedy mortality of the infant shortly after delivery due to infection, cardiac failure, or hypoxemia. ${ }^{4}$ Attempts at surgical correction have been largely unsuccessful.

The delivery of viable fetus should be atraumatic by caesarean section in the presence of multidisciplinary medical team of gynecologist, neonatologist, pediatric cardiologist, and pediatric surgeon. ${ }^{9}$ The prognosis of its survival after delivery is guarded by location of the defect, extent of intracardiac defects and associated abnormalities with thoracic ectopia cordis carrying the best prognosis. ${ }^{10}$

\section{CONCLUSIONS}

Ectopia cordis is a rare congenital malformation with a complicated prognosis related to associated anomalies and a possible X-linked inheritance. Given the speedy mortality after birth, unsuccessful surgical correction and increasing availability of ultrasound, this case could be diagnosed early in pregnancy followed by pregnancy termination.

\section{ACKNOWLEDGEMENT}

I would like to thank my wife Mrs. Sapana Shrestha for her help during the preparation of the manuscript of this article.

\section{DISCLOSURE}

The authors report no conflicts of interest in this work. No violation of human rights and safety. Funding: nil.

\section{REFERENCES}

1. Pepper MA, Fishbein GA, Teitell MA. Thoraco-abdominal wall defect with complete ectopia cordis and gastroschisis. Pediatr Dev Pathol. 2013;16:348-52.

2. Kanagasuntheram R,Verzin JA. Ectopia cordis in man. BMJ $1962 ; 17: 159$

3. Millhouse RF, Joos HA. Thoracic ectopia cordis and associated extra-cardiac anomalies. Am Heart J. 1959;57(3):470-6.

4. Madhavi D, Rajasree TK. Thoracic Ectopia Cordis - a case report. IJBR. 2012;3(1):69-73

5. Hannoun A, Usta IM, Sawaya F, Nassar AH. First trimester sonographic diagnosis of ectopia cordis. J Matern Fetal Neonatal Med. 2011;24(6):867-9.
6. Khoury MJ, Cordero JF, Rasmussen S. Ectopia cordis, midline defects and chromosome abnormalities: an epidemiologic perspective. Am J Med Genet. 1988;30:811-7.

7. Cantrell JR, Haller JA, Ravitch MM. A syndrome of congenital defects involving the abdominal wall, sternum, diaphragm, pericardium and heart. Surg Gynecol Obstet. 1958;107:602-614.

8. Achiron R, Schimmel M, Farber B, Glaser J. Prenatal sonographic diagnosis and perinatal management of ectopia cordis. Ultra sound Obstet Gynecol J.1991;431-4.

9. Alphonso N, Venugopal P, Deshpande R, Anderson D. Complete thoracic ectopia cordis. Eur J Cardiothorac Surg. $2003 ; 23: 426-8$.

10. Chishugi JB, Franke TJ. Thoraco-abdominal ectopia cordis. Pan African Medical Journal. 2014;18:124. 